\title{
Conceptualizing Narratives in Gamified Information Systems
}

\author{
Manuel Schmidt-Kraepelin \\ Karlsruhe Institute of \\ Technology \\ $\underline{\text { manuel.schmidt-kraepelin@kit.edu }}$
}

\author{
Simon Warsinsky \\ Karlsruhe Institute of \\ Technology \\ simon.warsinsky@kit.edu
}

\author{
Scott Thiebes \\ Karlsruhe Institute of \\ Technology \\ scott.thiebes@kit.edu
}

\author{
Ali Sunyaev \\ Karlsruhe Institute of \\ Technology \\ sunyaev@kit.edu
}

\begin{abstract}
Converging hedonic and utilitarian elements under the label of gamification has become an important phenomenon in information systems over the last decade. Yet, academic discourse on narratives in gamified IS remains scarce. To advance scholarly engagement, this study recontextualizes the concept of narratives for gamified IS. Based on the theoretical lens of hedonic and utilitarian consumption, we conducted a hermeneutic literature review in which we engaged with existing conceptualizations of narratives in a total of 84 studies across various disciplines. Results include a basic conceptualization of narratives complemented by six claims that may shape our way of thinking about narratives in gamified IS. Our findings contribute to a more comprehensive understanding of narratives in gamified IS that goes beyond that of traditional game elements. It may serve as a cornerstone for further discourse on narratives and how to meaningfully design them in gamified IS.
\end{abstract}

\section{Introduction}

Over the last decade, gamification has become one of the most important phenomena in information systems (IS) with a vast amount of peer-reviewed publications being published and, not less, gamified applications being deployed in practice [1]. While the first wave of gamification research aimed to answer the plain question of whether gamification works, subsequent studies have started to delve deeper into theoretically explaining and empirically measuring the effects of gamification [2,3]. Thereby, researchers mainly focused their attention on elements that one would traditionally associate with gamification, such as points, goals, badges, or leaderboards [4]. Although extant research has often argued that narratives are an integral part of almost every (video) game, only little academic attention has been paid toward narratives as part of meaningful gamification design [5]. In addition, extant research has even shown that elements of fictional narratives (e.g., fantasy) are hardly found in real-world gamified applications [6]. At first glance, this seems surprising since in the beginning of the academic discourse on gamification, gamified IS with sophisticated storylines, such as the app Zombies, Run!, have often been hailed as prime examples of good gamification design.

One reason for this lack of scholarly inquiry on narratives in gamified IS could be that extant research disagrees on what narratives actually are and often confuses narratives with related concepts such as storytelling [5]. This becomes clear when looking at existing conceptualizations through the lens of the famous MDA framework [7]. Some researchers define narratives as a sequence of events while performing an activity or task and, thus, view narratives primarily as game mechanics [5]. Others argue that narratives are game dynamics that emerge while interacting with a game or gamified IS [e.g., 8], while still others argue that narratives are game aesthetics which represent the player's experience of the game as a drama [7]. This confusion surrounding the concept has not yet been sufficiently approached, as many well-cited typologies of gamification elements [e.g., 9, 10] neglect narratives completely in their lists. Zichermann and Cunningham [11] even state that they "generally ignore narrative structure in gamification because [they] are building 'nonfiction' experiences." Furthermore, the basic assumption that narratives in gamified IS are sufficiently captured when solely being understood as game elements has to be questioned when engaging with work of influential narrative theorists. For example, Jerome Bruner famously argued for conceptualizing life itself as a narrative that is constructed by human beings through active ratiocination [12] and Alasdair MacIntyre stated in his seminal work After Virtue that "we all live out narratives in our lives and [...] we understand our own lives in terms of the narratives that 
we live out [...]. The form of narrative is appropriate for understanding the actions of others" [13]. Such interpretations of the narrative concept inevitably lead to the assumption that narratives may go beyond 'traditional' game elements in the sense of the MDA framework and, thus, should be of interest to any provider of a gamified IS.

Given the conceptual complexity and ambiguity surrounding narratives, we think that to advance scholarly engagement, we need to rethink our approach for understanding narratives in gamified IS. Aligning our approach with that of Boell and Cecez-Kecmanovic [14], who conceptualized information for IS research, we engaged with existing definitions of narratives from various scientific fields, including psychology, narratology, and game design. In these research areas scholars have studied narratives for decades. However, since gamified IS, unlike video games, are not purely hedonic, but rather represent a convergence of utilitarian and hedonic system characteristics [4], we did not assume easy transferability of knowledge. Instead, while engaging with the literature, we took hedonic and utilitarian consumption as the theoretical lens to analyze our conceptualization and its impact on the outcomes of gamified IS.

Based on our engagement with the literature, we developed a basic understanding of the narrative concept and its different perspectives. We then developed six claims that shine light on the most relevant characteristics of narratives in the context of gamified IS. Our research contributes to a deeper understanding of the narrative concept in gamified IS by rethinking its conceptualization and, thereby, laying the foundation for profound theory building. In doing so, we take the first step toward answering calls for more native theory-building in gamification research [1]. For practitioners, the conceptualization can be used as an inspirational starting point to think about the design of interesting and effective narratives in gamified IS. However, more research will be necessary to provide them with substantiated design guidelines.

The remainder of this paper is structured as follows. Section two provides the background on narratives in gamified IS as well as hedonic and utilitarian consumption. Our research approach is described in section three. The conceptualization of narratives in gamified IS is presented in section four and discussed in section five. Section six briefly concludes our paper.

\section{Theoretical background}

\subsection{Narratives in gamified information systems}

Broadly speaking, gamification refers to developments within technology, economy, culture, and society in which reality becomes more gameful [15]. Two types of gamification may be differentiated [15]: (1) intentional gamification (i.e., the intentional process of transforming a system to afford more gameful experiences), and (2) emergent gamification (i.e., a general cultural and societal transformation stemming from an increased engagement with games and gameful interactions). While there have been many positive developments in gamification research over the last years (e.g., more theory-driven rigorous empirical studies instead of solely measuring simple outcomes of gamification [2]), gamification research has also received some criticism. Some authors complain that gamification research has too often relied on the same artefacts of theory (e.g., self-determination theory) and desperately needs more native theories [1]. Others pointed out that research and practice have been too limited to the same elements of "structural gamification" (i.e., game elements are added to the structure of the content, but the content itself remains unaltered [16]), which is commonly referred to as the points, badges, leaderboards (PBL) triad [17]. Thereby, promising aspects of gamification such as engaging narratives have been primarily treated as side notes if at all.

Extant research on narratives in gamified IS is rather scarce. Some studies use the term narrative conceptually similar or very close to that of story or storyline [e.g., 17, 18, 19, 20]. They primarily deal with narratives as a game element that is consciously implemented by the provider of the gamified IS to evoke elements of fantasy or fiction and, thereby, make system use more emotionally appealing [9]. In this context, authors often state that narratives are inherently sequential and contain a series of events [e.g., 18, 19]. Other authors emphasize that narrative is a broader concept that may include but is not limited to storytelling [21]. One study that did not limit its conception of narratives to be a game element directly implemented in a gamified IS is that of Nicholson [22]. While reporting his RECIPE guidelines for meaningful gamification, he emphasizes the importance of allowing users to create their own narratives during the exposition phase of system use. Thereby, he draws on the work of Simons [23] and defines narratives as a "core pattern for cognition, comprehension, and explanation [that] is the most important tool for construing identities and histories". Furthermore, a first approach toward finding a contextualized definition of narratives for gamification was made by Palomino, et al. [5], who reviewed literature from different fields (e.g., literary studies, digital games, and communication). Their results include ten possible features of narratives, and they develop the following definition: "[A narrative is] the process in which the user builds his own experience 
through a given content, exercising their freedom of choice in a given space and period of time, bounded by the system's logic." While providing a strong and substantial contribution to the debate surrounding narratives in gamification, their study is limited to the context of educational systems, and they only consider four of the most prevalent definitions for narratives. Overall, given the current landscape of research regarding narratives in gamified IS, we think that there is still a need for further engaging with the literature to conduct a comprehensive recontextualization of narratives for gamified IS. Future theorizing might benefit from a conceptualization of narratives that considers the particularities of gamified IS (i.e., the combination of hedonic and utilitarian value) while at the same time not being bound to a single application context (e.g., education, fitness).

\subsection{Hedonic and utilitarian consumption}

Deeply rooted in the area of marketing, extant research has developed the notion that consumption of products can take place for hedonic or utilitarian reasons [e.g., 24, 25]. Hedonic consumption is mainly understood as the multisensory aspects of one's experience with products including tastes, sounds, tactile impressions and visual images [24]. Such hedonic experience primarily arises from products that tend strongly to evoke heightened levels of fantasies, feelings and fun [25]. Consequently, hedonic products are primarily consumed for affective purposes as they contain an intrinsic self-fulfilling value for the consumer [26]. Classic examples of hedonic products can be found in the entertainment industry (e.g., movies, video games, or novels [24]). By contrast, utilitarian consumption refers to the use of a product for its objective functional purpose [24]. Utilitarian products possess a stronger rational appeal and are regarded as less emotionally arousing as they generally provide cognitively oriented benefits [26]. Typical examples mentioned in literature are a flashlight, a pen, or a can of motor oil [24]. With regard to utilitarian consumption, consumers are often viewed as rational decision makers as they evaluate products based on the instrumental value they provide [24].

IS researchers have relatively early adopted the original views on hedonic and utilitarian consumption [27]. Consequently, IS have traditionally been considered to be either hedonic (i.e., pleasure-oriented systems that provide self-fulfilled values to users) or utilitarian (i.e., productivity-oriented systems that provide instrumental value to users) [27]. Gamification researchers, however, have argued that gamified IS are systems in which both system types are converged [4]. For instance, gamified health applications should be fun to use and enjoyable (i.e., provide hedonic value) while at the same time providing users with support regarding the desired health behavior change (i.e., provide utilitarian value). In marketing research, similar mixed types of products and experiences have been studied. They are sometimes referred to as balanced products [24]. For example, various studies have demonstrated that shopping experiences often lead to both hedonic and utilitarian value [28]. Those studies have also argued that hedonic as well as utilitarian experiences both have a substantial effect on customer satisfaction for balanced products. In gamified IS, the convergence of hedonic and utilitarian aspects has similar implications. For instance, providers of gamified IS face the challenge of balancing pragmatic value and fun while developing their systems which leads to altered risk factors during development [29].

\section{Methods}

In order to recontextualize the concept of narratives for gamified IS, we conducted an extensive review of literature conceptually engaging with narratives within various disciplines. In particular, we were interested to learn how narratives are described and conceptualized by works in these disciplines. We followed the hermeneutic approach to literature reviews as proposed by Boell and Cecez-Kecmanovic [30]. Broadly speaking, the hermeneutic approach to literature reviews consists of two intertwined circles: (1) search and acquisition, and (2) analysis and interpretation. We chose a hermeneutic approach as it ensures a sufficient level of depth when it comes to developing a conceptualization based on a wide range of literature [14]. As the relevant body of literature is huge and spans various different disciplines and in order to get a thorough understanding of the wide range of different ways the narrative concept is used in the literature, breadth was of particular importance. As a starting point, we chose a convenience sample that consisted of articles that the authors were familiar with from past research inquires as well as the results of an unstructured initial database search. It included the most cited works on narratives in different disciplines such as psychology [e.g., 31], game design [e.g., 32], and philosophy [e.g., 33]. On the basis of this starting point we identified further relevant research by conducting forward and backward searches for references and citations [34], which led to an initial set of 29 articles. To ensure a sufficient level of breadth in our coverage of the literature, we augmented our approach with two keyword searches in the Scopus database. The literature search was initially conducted on December 22, 2020, but later updated on June 1, 2021. First, we used the search string TITLE-ABSTR-KEY (narrativ* AND 
(gamif* OR game)) to target the use of narratives in video games, thereby taking a primarily hedonic perspective. This first search yielded a total of 4,882 results. As suggested by Boell and Cecez-Kecmanovic [30], we reduced the set of articles based on the number of citations and only focused on studies that had 34 citations or more $(n=204)$. We screened the abstracts of all articles and excluded them if (1) they were not written in English $(n=0)$, or (2) did not focus on narratives $(n=94)$. For the remaining 110 articles, we analyzed their full-texts, and only included those which provided us with a clear conceptual understanding of narratives (e.g., by providing a definition). This resulted in the exclusion of 75 additional articles, yielding us a set of 35 articles. Second, to contrast the hedonic perspective, we used the search string TITLE-ABSTRKEY (narrativ* AND utilitarian), which provided us with a set of 198 papers. These articles were again reviewed using the exclude criteria as described above (28 articles were not written in English; 79 articles did not focus on narratives; 71 articles did not provide a clear conceptual understanding of narratives) which resulted in the identification of additional 20 relevant articles. Overall, we engaged with descriptions of the narrative concept in 84 different manuscripts while expanding our understanding and iteratively passing through the inner and the outer hermeneutic circle [30].

Our review focused on analyzing the different ways in which the narrative concept is described and used in the literature. In particular, we conducted a thematic analysis [35] and engaged with statements that were made about narratives when the concept was described and used in the literature. During data analysis, two of the authors directly engaged with the literature. In a first step, they extracted the most relevant statements with regard to conceptualizations of narratives which resulted in the identification of 318 relevant statements. Afterwards, both researchers conducted an open coding process of the relevant statements and iteratively discussed and refined their results. By following this approach, they developed 14 1st order concepts that described relevant characteristics and outcomes of narratives in gamified IS. Subsequently, they analyzed commonalities and differences across our set of 1 st order concepts to iteratively develop 2nd order concepts. The final set of 1 st order and 2 nd order concepts was then discussed with the remaining two authors and refinements were made based on their feedback. Of the 141 st order concepts, we used five to develop the basic conceptual understanding of narratives in gamified IS as they were concerned with the fundamental attributes of narratives (e.g., Narratives are means for sense-making of experiences). The remaining nine were consolidated to result in six additional claims about characteristics and outcomes of narratives in gamified IS. For example, the statement "[a] kernel is what makes us recognize the story; take away the kernel and the story is no longer the same. [...] Satellites are what can be replaced or removed while still keeping the story recognizable, but which defines the discourse [...]" [32] was initially coded as 1st order concept Narratives contain kernels and satellites. In addition, the statement "[A narrative] may be real or fantasy, based not on plausibility of facts, but rather on the integrity of structure internal to discourse" [36] was coded as Integrity of structure. Later, the two 1st order concepts were merged into the 2 nd order concept Narratives require plausibility (i.e., Claim 4). A list of analyzed manuscripts and links to the developed basic understanding and claims can be found in the online supplement material (https://bit.ly/2WR7Fba).

\section{Conceptualization of narratives in gamified information systems}

Our literature review unraveled a plethora of definitions, statements, and ideas made about narratives across various disciplines. In the following, we synthesize the knowledge that we gained by engaging with the literature. First, we provide a basic conceptual understanding of narratives in gamified IS, followed by a set of claims that may shape the way we need to think about narratives in gamified IS.

Aligning our view with that of narrative psychology [31], we understand narrative thinking as a type of causal thinking in which the narrative (cognitive) schema is used to identify categories (e.g., protagonist, situation, conflict, outcome) and relevant types of relationships (temporal, motivational, and procedural) [37]. In this heuristic process a narrative framework is used to integrate experiences (which do not necessarily occur in narrative form) into a plausible structure [37]. Narratives can be seen as both a means for sense-making of experiences [12] and a means of exchanging information with others [13]. They also serve the purpose of contextualizing particular content, thereby transforming it from facts or concepts to be memorized into useful tools to address significant issues [38]. An important distinction that one might make is that between narrative and story. Both terms are often used interchangeably in literature [5]. In this work, we differentiate both terms. Aligning our understanding with that of Crawford and Gosling [39] and Carr [40], we argue that a narrative can be understood as consisting of a story and discourses. While the story provides the resources for the narrative (i.e., the sequence of events that form the understandable composite of a narrative), the discourses (e.g., ideas, concepts, and categorizations [41]) shape the narratives in peoples' minds. 


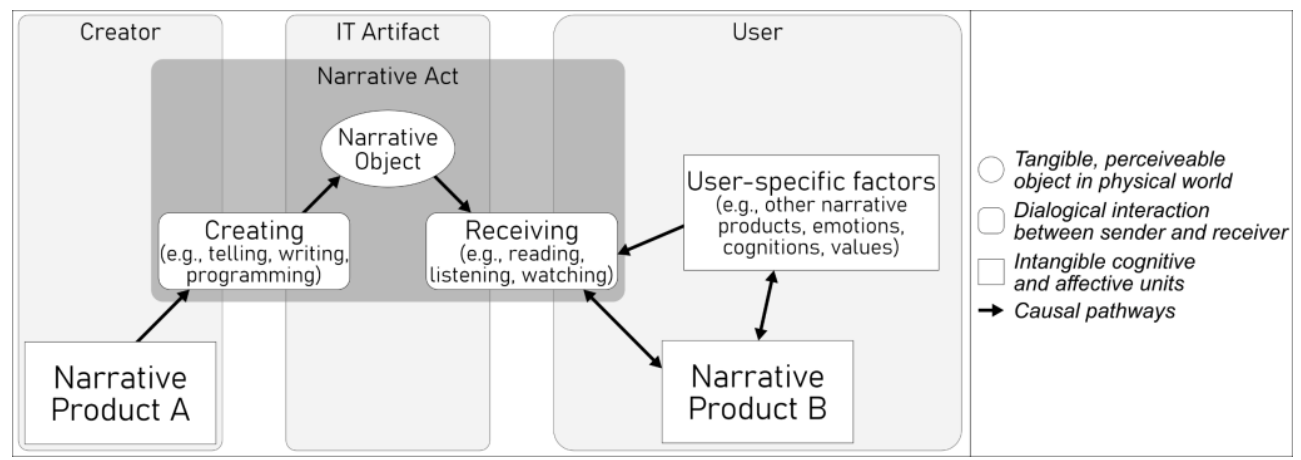

Figure 1. Different perspectives on narratives and their relation in gamified IS

An important issue when conceptualizing narratives is to recognize that narratives have a threeway product-act-object ambiguity - that is, the term narrative can be used threefold [42, 43]. First, narrative may refer to the product of narrative thinking (i.e., the narrative that is structured and memorized in someone's mind). It is sometimes referred to as a narrative when someone speaks of different versions of the same narrative. Second, the act of narration (e.g., the telling of a story) can also be classed as narrative, as in saying that the narrative lasted over an hour. Lastly, sometimes the narrative object (e.g., the written text in a book) is called a narrative, for example, when someone talks about reading a narrative. In order to have an informed discourse about narratives in gamified IS, it is important to separate these three perspectives for higher granularity. Figure 1 illustrates our understanding of how the three perspectives of narratives are related in a gamified IS. To begin with, our understanding is that the creator of a gamified IS draws on a narrative product in his mind to engage in the act of narration and create (e.g., write or orate) a tangible narrative object (e.g., a text or speech) that can be physically perceived and, thus, be received (e.g., read or listened to) by the user of the gamified IS. A new narrative product is then formed in the user's mind which is shaped by the narrative object itself, the act of narration (i.e., how the narrative is told), and user-specific cognitive-affective factors (e.g., other narrative products, emotions, values). Figure 1 is a simplified illustration. Within gamified IS it is, for example, also imaginable that the user influences the creation of the narrative object in realtime by interacting with the system (e.g., by making a particular decision on how a story unfolds). Prior literature on game design has referred to this phenomenon as emergent narratives as opposed to embedded narratives (i.e., pre-generated immutable narrative objects) [32].

In summary, we hold that our conceptualization of narratives so far includes that narratives are a means for sensemaking and exchanging information, that narratives are not equivalent to, but in fact comprise story, and that there are three distinct perspectives on narratives (i.e., product, act, object) in gamified IS. To further substantiate the concept, we derived six claims about narratives in gamified IS that describe their most important characteristics. Our first claim is strongly derived from our applied theoretical lens of hedonic and utilitarian consumption. Hence, we established this claim as Claim 0, which informed the development of the other claims. In the following, we briefly outline each claim and explain its relevance when engaging with narratives in gamified IS. Note that throughout the claims, we use the term narrative to refer to narrative products.

Claim 0: Narratives can convey both hedonic as well as utilitarian value. This basic claim roots narratives as a balanced product in the sense of hedonic and utilitarian consumption [24]. Interesting narratives in gamified IS often yield rich sensory experiences and are, thus, self-evidently appealing [38], which may manifest in hedonic value. From a utilitarian perspective, narratives carry implicit or explicit messages about a specific topic that is being addressed [44]. In gamified IS, the topic of a narrative may be related to the instrumental goals of the system (e.g., achieving an increase in physical activity in users). Thus, if cleverly designed and providing users with the right information at the right time, we claim that narratives in gamified IS can lead to utilitarian benefits for system users.

Claim 1: Narratives are mind-dependent. Narratives are constructed by human beings through active ratiocination [12] and, thus, are a product of human thought. As for any cognitive act, abstraction, schematization, and inference play a key role in shaping and memorizing a narrative [37]. As stated before, a narrative is also influenced by prior experiences, such as other narratives that are evaluated in perspective to the newly created narrative. Consequently, we argue that it is impossible for two narratives in different users' minds to exist that are exactly the same. When considering a narrative in a 
gamified IS, one has to not only focus on the story being told and the narrative object that is being created, but also pay attention to underlying discourses, as well as patterns of reception and interpretation [39]. For example, the reception of a narrative that is communicated by an organization may be affected by the recipients' perception of said organizations work ethics. Differences in reception and interpretation can also ripple through to the values that individuals draw from narratives. Whereas some individuals may derive enjoyment (i.e., hedonic value) from, for example, listening to an audio play, other individuals may be able to derive utilitarian value from it (e.g., by improving their foreign language skills).

Claim 2: Narratives have a hierarchical structure. Claim two states that narratives are connected to other related narratives through a hierarchical order. Familiarity and interpretation of higher order narratives may play a key role in developing discourses surrounding a sub-narrative and vice versa. This mechanism is, for example, used in TV series. Every viewer will be able to understand the narration of a single episode to some extent and build a narrative to make sense of it. However, the resulting narrative product would be substantially different if this viewer was familiar with the overall narrative of the TV series (including characters, events, conflicts etc.). Extant literature has also argued for the existence of so-called "master narratives" on the highest level of abstraction $[45,46]$. They can be described as those narratives capturing "the raw material out of which the social cosmology of a people is made, the assumptions built into deep ideology and deep structure, never to be questioned" [46]. Typical examples of such master narratives include the battle between good and evil, the search for enlightenment, or religious motives. When considering a narrative that is conveyed through a gamified IS, one has to be mindful that the user's reception of said narrative may be influenced by other (possibly higher order) narratives. When embracing the dual values of narratives in gamified IS, one also has to consider that the type of value (i.e., hedonic or utilitarian) a narrative conveys can differ per narrative and per user. If narratives overlap, their hierarchical structure may, for example, cause a narrative that affords mainly utilitarian value to overshadow one that affords mainly hedonic value (or vice versa). This highlights that in a gamified IS, the prevalence of each type of narrative has to be balanced to in turn afford balanced outcomes. In this light, one should also consider that conveying one narrative may result in the formation of several lower order sub-narratives, which in turn can influence users' narrative thinking as illustrated.
Claim 3: Narration is selective. For narratives to come into existence and be communicable, they must be transformed into a tangible narrative object (e.g., a text). Claim three states that a narrative object is only ever able to represent a part of the corresponding narrative. Similar to when information is encoded into a message, this transformation of a narrative into a narrative object is by nature not loss-free. Rather, narrative objects are necessarily selective, because "to sustain its thread, a narrative [object] must highlight some elements and leave others out" [47]. It is important to consider that when one "leaves out too much" in the transformation from narrative to narrative object, the explicit and implicit messages of a narrative may get lost in translation. As these messages are possibly tied to the instrumental goals of a gamified IS, their loss may also translate to a loss in utilitarian value. In gamified IS, the selectivity of narration emerges particularly because, similar to games, the run-time dynamics of the user's interaction with the system gives the user some control over the environment which also comes with control over how the narrative object is created [48]. To this end, it is important to consider that a narrative consists of constitutive elements that make us recognize a specific story and non-diegetic elements that can be altered while keeping the story intact [32]. For example, in the fairy tale Little Red Riding Hood, if the wolf does not eat Red and her Granny, the tale cannot be recognized as such, whereas the identity of the tale is not dependent on whether Red stops in the wood to pick a flower or not [32]. When investigating narratives in gamified IS, it is important to appraise whether a narrative object successfully conveys all the constitutive elements of the respective narrative and that none of these elements get lost in the interaction.

Claim 4: Narratives require plausibility. Claim four states that narratives require plausibility to be captured and memorized. In this regard, plausibility refers to the integrity of the narrative structure [49], characterized by its coherence as well as fidelity [50]. It determines the user's ability to capture the relevant categories (e.g., actors, events, conflicts) and their relationships (temporal, causal) [51]. Narrative thinking requires integrating experiences into a plausible story line to ultimately form a narrative [49]. Thus, there are by nature no implausible narratives in people's minds [12, 49]. Hence, if categories or relationships are not made explicit during the act of narration, recipients will make conscious or unconscious assumptions to maintain the plausibility of a narrative (e.g., assume that firearms do not exist in a medieval-themed fantasy world). In addition, implausibility of a conveyed narrative may jeopardize its self-appeal and thus, also jeopardize the narrative's 
hedonic value. Essentially, an incoherent narrative can make a story dull and not enjoyable. As an analogy that illustrates this, one may consider how the enjoyment of a book severely drops when one reads only every other page. When engaging with narratives in gamified IS, it is vital to be aware of this mechanism. For example, one should consider which parts of the narrative should be shaped through explicit statements, and which parts should be shaped through the user's own interpretations.

Claim 5: Narratives can lead to persuasive effects. The last claim states that narratives can lead to real-world belief and behavior change [52]. The mechanisms of this effect have been described in transportation theory and the transportation imagery model [53, 54]. Psychologically similar to flow [55], transportation into a narrative world is a form of experiential response to narratives [56]. It is defined as an integrative melding of attention, imagery, and feelings that is focused on narrative events and is affected by certain contextual and personal factors (e.g., a recipient's imagery skill) [57]. Narrative transportation theory proposes that when consumers lose themselves in a state of narrative transportation, their attitudes and intentions can change based on the explicit and implicit messages that are made about the narrative's topic (e.g., the implicit message that moral action pays off is conveyed to the recipient when the villain is brought to justice at the end of the story) [53]. Since the design and implementation of gamification is mainly done for achieving persuasive goals (e.g., getting users to be more physically active), this claim demonstrates that it is important to consider the persuasive power of narratives in gamified IS. In particular, one should be aware that narratives, regardless of whether one considers them fictional or non-fictional, can lead to persistent persuasive effects [52]. These persuasive effects can subsequently lead to real-world behavior change [54], which may then ultimately manifest in utilitarian value.

\section{Discussion}

\subsection{Principal findings}

In this study, we conducted a hermeneutic literature review [30] in order to engage deeply with literature on narratives and recontextualize the concept for gamified IS. By differentiating three perspectives on narratives (product, act, and object) and describing their interplay in a typical transfer of a narrative within a gamified IS, our conceptualization gives initial insight into the (cognitive) processes involved. While earlier research has recognized and described the three-way product-act-object ambiguity [42, 43], we conceptualize and illustrate their interplay and, thereby, show a way of resolving this ambiguity. Based on our conceptualization, we argue that we should further build on this stream of research and expand our understanding of narratives beyond that of game elements. While certainly being implementable in gamified IS as narrative objects, and interacted with during the narrative act, we think that it is important to understand that the narrative product that is actually memorized by users is influenced by many other factors (e.g., other narratives) that may be within or beyond the control of gamified IS providers.

By deriving six claims about narratives in general and briefly discussing their relevance for gamified IS, we were able to further emphasize those characteristics of narratives that are of particular interest in the context of gamified IS. Thereby, our claims may roughly be categorized as being either outcome-oriented (i.e. describing potential outcomes of narratives in gamified IS; Claim 0 and 5) or structure-oriented (i.e. describing the structure of narratives in gamified IS; Claims 1-4). By synthesizing our knowledge through the lens of hedonic and utilitarian consumption, we conclude that narratives can provide users of gamified IS with selffulfilling as well as instrumental value. This view contradicts extant research that has argued that narratives primarily yield hedonic value and that utilitarian value should be conveyed through messages based on rationality, proofs, and expressions of certain knowing [58]. At first sight, this seems logical, when looking at the position of narratives as a fundamental form of thinking for humans, whose self-evident appeal [38] manifests in hedonic value. However, by harnessing its persuasive potential and, thereby, conveying important messages about the intended outcomes, narratives can help users reach their goals (e.g., achieving sustained behavior change) and, thus, lead to utilitarian benefits. As gamified IS should be seen as balanced products in the sense of hedonic and utilitarian consumption [24], we think that this duality of outcomes makes narratives a good fit with great potential to be part of meaningful gamification design. Today, the state of research regarding hedonic and utilitarian narratives is rather scarce. However, first studies exist that support our arguments [59].

A popular approach is to classify narratives into being either fictional (i.e., narratives that are made-up in a creative process) or non-fictional such as firsthand experiential narratives based on everyday experiences [e.g., 52]. In this study, we made a conscious decision not to make this distinction a subject of our research. Instead, we argue that our basic conceptualization as well as our claims hold for all types of narratives. Further, we think that when arguing on a conceptual 
level it is in most cases not useful to distinguish between fictional and non-fictional narratives. On the one hand, every fictional narrative will carry some elements of discourse that are shaped by the creator's real-world experiences. On the other hand, everyday non-fictional narratives are augmented with fictional aspects as soon as they are internalized since "abstraction, schematization, and inference are part of any cognitive act” [37].

\subsection{Implications}

For research, our findings contribute to a more comprehensive understanding of narratives in gamified IS. We think that it is vital for research to investigate narratives not only as a game element in a gamified IS, but also in light of the narrative act and the narrative product that is formed by the user. By separating the overall concept of narratives into narrative product, act, and object and outlining these perspectives in gamified IS, we provide researchers with a way to shape the scientific discourse on narratives in gamified IS in a more granular way. Our findings highlight that through mechanisms such as narrative transportation, narratives can convey value, have persuasive effects, and ultimately lead to realworld behavior change [37]. The results, thus, strengthen our view of narratives as a highly fruitful ground to support the persuasive goals of a gamified IS. However, we also found that transportation into a narrative world may take place differently in gamified IS than in other contexts. For example, in light of the necessary plausibility of narratives, transportation can be affected when a narrative is in conflict with a possibly underlying ludic structure that a gamified IS borrows from games. Recent research has started to investigate this phenomenon under the term ludonarrative dissonance [45]. These developments demonstrate the utility of our work for future native theory building surrounding narratives in gamified IS.

For practitioners, our results have several implications regarding the design of meaningful narratives in gamified IS. The results highlight that for a narrative to support the persuasive goals of a gamified IS, it must fit the context as well as intended behavior change. Designers of gamified IS should, thus, be mindful of what explicit and implicit messages their narrative conveys, and, because of the selectiveness of narration, ensure that their narrative object successfully conveys all constitutive elements. Our results also imply that designers should not only lay their focus on the story being told or the narrative object being created, but also pay attention to underlying discourses, as well as patterns of reception and interpretation exhibited by the users. Lastly, practitioners should consider plausibility as a key factor for the designing narratives in gamified IS.

\subsection{Limitations and future research}

We acknowledge several limitations of our study. First, as we conducted a hermeneutic literature review as proposed by Boell and Cecez-Kecmanovic [30], we did not conduct a comprehensive systematic search. Instead, we started off with a convenience sample and augmented our literature basis through forward and backward search, as well as two small scale keywordbased searches limited to the Scopus database. While we acknowledge the possibility that this approach may have led to important work not being identified, we think that the hermeneutic approach provided us with enough freedom to ensure sufficient levels of depth and breadth. Overall, we engaged with 84 different manuscripts and our approach showed high levels of theoretical saturation in the last iterations of the hermeneutical circles. Nevertheless, future research could go one step further and aim to synthesize the thousands of manuscripts concerning narratives more comprehensively through systematic searches and thereby augment our conceptualization and potentially identify additional relevant claims. Second, the thematic analysis of narrative conceptualizations might have been prone to subjectivity, despite our efforts to triangulate data within the author team (i.e., having multiple authors engage with the literature). This potentially led to a lack of consistency and cohesion. In other words: other authors might have come up with claims on different abstraction levels. For future research, it may thus be interesting to employ different data analysis techniques that ensure a higher level of objectivity, such as grounded theory approaches [35]. Third, while providing a first recontextualization of the narrative concept for gamified IS, our research does not provide any prescriptions for how to design interesting and meaningful narratives (e.g., we claim that narratives can lead to persuasive effects, but do not provide concrete guidelines on how to achieve them). However, we think that future research could use our basic understanding and our claims as starting points to develop such prescriptions. Fourth, although all our claims are deeply rooted in decades of research on narratives and some of them have been subject of extensive empirical research, we do not provide any empirical evidence whether the claims also hold for narratives in gamified IS. However, we are confident that future research can fill this gap by empirically investigating and potentially verifying the mechanisms that we describe. 


\section{Conclusion}

In this study, we recontextualized the concept of narratives for gamified IS. To this end, we conducted a hermeneutic literature review and engaged with descriptions of the narrative concept in a total of 84 studies from various disciplines. We provide a basic conceptualization and six claims that describe the most relevant characteristics of narratives in gamified IS. Our results reveal narratives as a concept that transcends the abstraction level of game elements. Rather, we align our perspective with that of narrative psychology and conceptualize narratives as something that is ubiquitous, deeply hard-wired in the human mind, and may convey both hedonic as well as utilitarian value. Overall, we think that gamified IS are fertile soil to build sophisticated and meaningful narratives that can ultimately support desired psychological and behavioral outcomes. We, thus, encourage future research to further engage with the concept of narratives in gamified IS.

\section{References}

[1] Lowry, P.B., Petter, S., and Leimeister, J.M., "Desperately seeking the artefacts and the foundations of native theory in gamification research: why information systems researchers can play a legitimate role in this discourse and how they can better contribute", European Journal of Information Systems, 2020, 29(6), 609-620.

[2] Nacke, L.E., and Deterding, C.S., "The maturing of gamification research", Computers in Human Behaviour, 2017, 450-454.

[3] Schmidt-Kraepelin, M., Warsinsky, S., Thiebes, S., and Sunyaev, A., "The Role of Gamification in Health Behavior Change: A Review of Theory-driven Studies", 53rd Hawaii International Conference on System Sciences, Maui, HI, Jan. 7-10, 2020.

[4] Koivisto, J., and Hamari, J., "The rise of motivational information systems: A review of gamification research", International Journal of Information Management, 2019, 45, 191-210.

[5] Palomino, P.T., Toda, A.M., Oliveira, W., Cristea, A.I., and Isotani, S., "Narrative for gamification in education: why should you care?", 19th International Conference on Advanced Learning Technologies, Maceió, Brazil, Jul. 15-18, 2019.

[6] Schmidt-Kraepelin, M., Thiebes, S., and Sunyaev, A., "Investigating the Relationship between User Ratings and Gamification-a Review of Mhealth Apps in the Apple App Store and Google Play Store", 52nd Hawaii International Conference on System Sciences, Grand Wailea, Maui, Hawaii, USA, Jan. 08-11, 2019.

[7] Hunicke, R., LeBlanc, M., and Zubek, R., "MDA: A formal approach to game design and game research", AAAI Workshop on Challenges in Game AI, San Jose, CA, USA, 2004.
[8] Trinidad, M., Calderón, A., and Ruiz, M., "GoRace: A Multi-Context and Narrative-Based Gamification Suite to Overcome Gamification Technological Challenges", IEEE Access, 2021, 9, 65882-65905.

[9] Thiebes, S., Lins, S., and Basten, D., "Gamifying information systems-a synthesis of gamification mechanics and dynamics", European Conference on Information Systems, Tel Aviv, Israel, Jun. 09-11, 2014.

[10] Blohm, I., and Leimeister, J.M., "Gamification", Business \& information systems engineering, 2013, 5(4), 275-278.

[11] Zichermann, G., and Cunningham, C., "Gamification by design: Implementing game mechanics in web and mobile apps", O'Reilly Media, 2011.

[12] Bruner, J., "Life as narrative", Social research: An international quarterly, 2004, 71(3), 691-710.

[13] MacIntyre, A., "After virtue", A\&C Black, 2013.

[14] Boell, S., and Cecez-Kecmanovic, D., "What is 'Information'beyond a definition?", 36th International Conference on Information Systems, Forth Worth, TX, USA, Dec. 13-16, 2015.

[15] Hamari, J., "Gamification": In The Blackwell Encyclopedia of Sociology, Ritzer, G., 2019, John Wiley \& Sons, New York, NY, USA.

[16] Kapp, K.M., "The gamification of learning and instruction fieldbook: Ideas into practice", John Wiley \& Sons, 2013.

[17] Werbach, K., and Hunter, D., "For the win: How game thinking can revolutionize your business", Wharton School Press, 2012.

[18] Schmidt-Kraepelin, M., Thiebes, S., Schöbel, S., and Sunyaev, A., "Users' game design element preferences in health behavior change support systems for physical activity: A best-worst-scaling approach", 40th International Conference on Information Systems, Munich, Germany, Dec. 15-18, 2019.

[19] Toda, A.M., Oliveira, W., Klock, A.C., Palomino, P.T., et al., "A taxonomy of game elements for gamification in educational contexts: Proposal and evaluation", 19th International Conference on Advanced Learning Technologies, Maceió, Brazil, Jul. 15-18, 2019.

[20] Marczewski, A., "Even Ninja Monkeys like to play", London: Blurb Inc, 2015,

[21] Armstrong, M.B., and Landers, R.N., "Gamification of employee training and development", International Journal of Training and Development, 2018, 22(2), 162-169.

[22] Nicholson, S., "A recipe for meaningful gamification": In Gamification in education and business, 2015, Springer,

[23] Simons, J., "Narrative, games, and theory", Game studies, 2007, 7(1),

[24] Addis, M., and Holbrook, M.B., "On the conceptual link between mass customisation and experiential consumption: an explosion of subjectivity", Journal of Consumer Behaviour: An International Research Review, 2001, 1(1), 50-66.

[25] Holbrook, M.B., and Hirschman, E.C., "The experiential aspects of consumption: Consumer 
fantasies, feelings, and fun", Journal of consumer research, 1982, 9(2), 132-140.

[26] Lim, E.A.C., and Ang, S.H., "Hedonic vs. utilitarian consumption: A cross-cultural perspective based on cultural conditioning", Journal of business research, 2008, 61(3), 225-232.

[27] Van der Heijden, H., "User acceptance of hedonic information systems", MIS quarterly, 2004, 28(4),

[28] Gilboa, S., and Vilnai-Yavetz, I., "Shop until you drop? An exploratory analysis of mall experiences", European Journal of Marketing, 2013, 47(1),

[29] Warsinsky, S., Schmidt-Kraepelin, M., Thiebes, S., and Sunyaev, A., "Are Gamification Projects Different? An Exploratory Study on Software Project Risks for Gamified Health Behavior Change Support Systems", 54th Hawaii International Conference on System Sciences, Virtual Conference, Jan. 04-07, 2021.

[30] Boell, S.K., and Cecez-Kecmanovic, D., "A hermeneutic approach for conducting literature reviews and literature searches", Communications of the association for information systems, 2014, 34(1), 12.

[31] Sarbin, T.R., "Narrative psychology: The storied nature of human conduct", Praeger Publishers/Greenwood Publishing Group, 1986.

[32] Aarseth, E., "A narrative theory of games", International Conference on the Foundations of Digital Games, Raleigh, NC, USA, May 29 - Jun. 1, 2012.

[33] Ricoeur, P., "Time and narrative, Volume 3", University of Chicago Press, 2014.

[34] Webster, J., and Watson, R.T., "Analyzing the past to prepare for the future: Writing a literature review", MIS quarterly, 2002, xiii-xxiii.

[35] Ezzy, D., "Qualitative analysis", Routledge, 2013.

[36] Dickey, M.D., "Engaging by design: How engagement strategies in popular computer and video games can inform instructional design", Educational Technology Research and Development, 2005, 53(2), 67-83.

[37] Robinson, J.A., and Linda, H., "Narrative Thinking as a Heuristic Process": In Narrative Psychology: The Storied Nature of Human Conduct, Sarbin, T.R., 1986, Praeger Publishers, Westport, CT, USA.

[38] Barab, S.A., Sadler, T.D., Heiselt, C., Hickey, D., and Zuiker, S., "Relating narrative, inquiry, and inscriptions: Supporting consequential play", Journal of science education and technology, 2007, 16(1), 59-82.

[39] Crawford, G., and Gosling, V.K., "More than a game: Sports-themed video games and player narratives", Sociology of Sport Journal, 2009, 26(1), 50-66.

[40] Carr, D., "Games and Narrative": In Computer games: Text, narrative \& play, Carr, D., Buckingham, D., Burn, A., and Schott, G., 2006, Polity, Cambridge, UK.

[41] Hajer, M.A., "The politics of environmental discourse: Ecological modernization and the policy process", 1995 ,

[42] Lamarque, P., "On not expecting too much from narrative", Mind \& Language, 2004, 19(4), 393-408.

[43] Wilson, G.N., "Narrative": In The Oxford Handbook of Aesthetics, Levinson, J., 2003, Oxford University Press, Oxford, UK.

[44] Kreuter, M.W., Green, M.C., Cappella, J.N., Slater, M.D., et al., "Narrative communication in cancer prevention and control: a framework to guide research and application", Annals of behavioral medicine, 2007, 33(3), 221-235.

[45] Howe, L.A., "Ludonarrative dissonance and dominant narratives", Journal of the Philosophy of Sport, 2017, 44(1), 44-54.

[46] Hackett, R.A., and Zhao, Y., "Challenging a master narrative: Peace protest and opinion/editorial discourse in the US press during the Gulf War", Discourse \& Society, 1994, 5(4), 509-541.

[47] Foley, F., "The (de) legitimation of torture: rhetoric, shaming and narrative contestation in two British cases", European Journal of International Relations, 2021, 27(1), 102-126.

[48] Young, R.M., and Riedl, M., "Towards an architecture for intelligent control of narrative in interactive virtual worlds", 8th international conference on Intelligent user interfaces, Miami, FL, USA, Jan. 12-15, 2003.

[49] Dickey, M.D., "Murder on Grimm Isle: The impact of game narrative design in an educational game-based learning environment", British journal of educational technology, 2011, 42(3), 456-469.

[50] Kien, G., "Postmodernism trumps all: The world without facts", Qualitative Inquiry, 2021, 27(3-4), 374380.

[51] Riedl, M., Saretto, C.J., and Young, R.M., "Managing interaction between users and agents in a multi-agent storytelling environment", 2nd International Joint Conference on Autonomous Agents and Multiagent Systems, Melbourne, Australia, Jul. 14-18, 2003.

[52] Appel, M., and Richter, T., "Persuasive effects of fictional narratives increase over time", Media Psychology, 2007, 10(1), 113-134.

[53] Van Laer, T., De Ruyter, K., Visconti, L.M., and Wetzels, M., "The extended transportation-imagery model: A meta-analysis of the antecedents and consequences of consumers' narrative transportation", Journal of consumer research, 2014, 40(5), 797-817.

[54] Green, M.C., and Brock, T.C., "In the mind's eye: Transportation-imagery model of narrative persuasion.": In Narrative impact: Social and cognitive foundations, Green, M.C., Strange, J.J., and Brock, T.C., 2002, Lawrence Erlbaum Associates Publishers, Mahwah, NJ, USA.

[55] Csikszentmihalyi, M., and Csikzentmihaly, M., "Flow: The psychology of optimal experience", Harper \& Row, 1990.

[56] Green, M.C., "Narratives and cancer communication", Journal of communication, 2006, 56(1), 163-183.

[57] Green, M.C., and Brock, T.C., "The role of transportation in the persuasiveness of public narratives", Journal of personality and social psychology, 2000, 79(5), 701.

[58] Pérez, A., García de los Salmones, M.d.M., and Baraibar-Diez, E., "Effects of the Type of CSR Discourse for Utilitarian and Hedonic Services", Sustainability, 2020, 12(12), 4821.

[59] Golovacheva, K., Muravskii, D., Smirnova, M., and Muravskaia, S., "Using a narrative in sales promotions: An online vignette study", 4th International GamiFIN Conference, Levi, Finland, Apr. 1-3, 2020. 